\title{
The Characteristic Modes and Structures of Bluff-Body Stabilized Flames in Supersonic Coflow Air
}

\author{
Jiho Kim* and Youngbin Yoon** \\ School of Mechanical and Aerospace Engineering, Seoul National University, Seoul, KOREA

\section{Chul Woung Park***} \\ Center for Photometry \& Radiometry, Korea Research Institute of Standards and Science, Taejon, KOREA
}

\section{Jae Won Hahn****}

School of Mechanical Engineering, Yonsei University, Seoul, KOREA

\begin{abstract}
The stability and structure of bluff-body stabilized hydrogen flames were investigated numerically and experimentally. The velocity of coflowing air was varied from subsonic velocity to a supersonic velocity of Mach 1.8. OH PLIF images and Schlieren images were used for analysis. Flame regimes were used to classify the characteristic flame modes according to the variation of the fuel-air velocity ratio, into jet-like flame, central-jet-dominated flame, and recirculation zone flame. Stability curves were drawn to find the blowout regimes and to show the improvement in flame stability with increasing lip thickness of the fuel tube, which acts as a bluff-body. These curves collapse to a single line when the blowout curves are normalized by the size of the bluff-body. The variation of flame length with the increase in air flow rate was also investigated. In the subsonic coflow condition, the flame length decreased significantly, but in the supersonic coflow condition, the flame length increased slowly and finally reached a near-constant value. This phenomenon is attributed to the air-entrainment of subsonic flow and the compressibility effect of supersonic flow. The closed-tip recirculation zone flames in supersonic coflow had a reacting core in the partially premixed zone, where the fuel jet lost its momentum due to the high-pressure zone and followed the recirculation zone; this behavior resulted in the long characteristic time for the fuel-air mixing.
\end{abstract}

Key words: bluff-body stabilized flame, supersonic flame, flame stability, Damköhler number

\section{Nomenclature}

$B R$

$d_{F, i}$

$d_{F, o}$

$L_{f}$

$U_{m, A}$ blockage ratio $\left(=d_{F, o}^{2} / d_{A}^{2}\right)$

inner diameter of fuel tube

outer diameter of fuel tube, diameter of

bluff body

flame length

air mass-weighted velocity

$\left(=\rho_{A} U_{A} / \rho_{A, \text { ref }}=\dot{m} A /\left(\rho_{A, r e f} A_{A}\right)\right)$
$U_{m, F} \quad$ : fuel mass-weighted velocity

$\left(=\rho_{F} U_{F} / \rho_{F, \text { ref }}=\dot{m}_{F} /\left(\rho_{F, r e f} A_{F}\right)\right)$

$\tau$

$\rho_{A} U_{A} \quad$ : air mass flux

$\rho_{F} U_{F} \quad$ : fuel mass flux

$\tau_{R, A} \quad$ : global residence time of air $\left(d_{F, i} / U_{m, A}\right)$

$\tau_{R, F} \quad$ : global residence time of fuel $\left(d_{F, i} / U_{m, F}\right)$
This is an Open Access article distributed under the terms of the Creative Commons Attribution Non-Commercial License (http://creativecommons.org/licenses/by$\mathrm{nc} / 3.0 /$ ) which permits unrestricted non-commercial use, distribution, and reproduction in any medium, provided the original work is properly cited. (c) * Senior Research Engineer, Hyundai Motor Company ** Professor, Corresponding author: ybyoon@snu.ac.kr $* * *$ Senior Researcher $* * * *$ Professor 


\section{Introduction}

Bluff-body nozzles are basic devices for stabilizing both premixed flames and non-premixed flames. The coflow air entrains a part of the central fuel jet into the low-speed recirculation zone in the wake of the bluff body, and then combustion mixing stabilizes the flame. With a bluff body, the flame characteristic changes from a pure diffusion flame, classically stabilized on the burner surface, to a partially premixed flame stabilized in the recirculation zone [1].

The structure of bluff-body stabilized flames has been investigated by numerous researchers. The relation between flame structure and flame stability was identified. Kundu et al. [2] investigated flame stabilization by bluff-bodies to highlight the role of the recirculation zone. They observed that close correlations exist between heat exchange from the recirculation zone and flame stability, which were controlled by the strength of recirculation. Roquemore et al. [3] studied the dynamic behavior of bluff-body diffusion flames by using spectrophotometers. They found largescale turbulence downstream of the recirculation zone, and showed a quasi-periodic decrease in frequency of the turbulence with the distance from the exit. Masri and Bilger [4] classified three flame types based on the penetration of the central jet through the recirculation bubble: short flame, transitional flame, and central fuel jet-dominated flame. However, most flames were classified according to the fuel/ air velocity or momentum ratio. Huang and Lin [5] identified seven characteristic flame modes: recirculated, transition, unsteady detached, laminar ring, developing, split flashing and lifted flame modes. Chen et al. [6] defined a detailed regime diagram for flame lift-off and stabilization limits, and classified the bluff-body stabilized flames: recirculation zone, jet-dominated, and jet-like flames. They showed that lift-off stability is more sensitive to the coflow air velocity than to the fuel jet velocity.

In recent studies, laser diagnostics were used to obtain more details on flame structures. Chin and Tankin [7] used a laser sheet lightening technique for low-Reynolds-number flows in a two-dimensional vertical bluff body burner. They defined three regimes according to the fuel penetration into the recirculation zone: pre-penetration, penetrationtransition and penetration regimes. Masri et al. [8] measured the mixture fractions, temperatures, and $\mathrm{OH}$ radicals of the flames to reveal the structure of the recirculation zone in a bluff-body stabilized flame by using a joint Raman-RayleighLIF image technique. They found that double reaction structures appear more frequently, and these structures shift to the center of the main vortex as the fuel-to-air velocity ratio increases. Using PLIF imaging, Yang et al. [9] found that the position of the reaction zone moves upstream from the outer shear layer of the air driven vortex as the velocity ratio increases. Yang et al. [10] also showed that the recirculation zone bubble provides a low-velocity environment and prolongs the stagnation of the reactant. The stagnation prolongation is a key factor for stabilizing the flame as the fuel-air velocity ratio becomes large.

Bluff-body nozzles play an important role in stabilizing flames in supersonic coflow air [11]. However, few studies have focused on supersonic flames, especially bluff-body stabilized flames featuring elevated flow velocities up to supersonic conditions. Cheng et al. [12] measured the temperatures and the concentrations of several species in a supersonic combustor by using UV Raman scattering and LIPF (Laser-Induced Predissociative Fluorescence). They reported that more intense turbulent fluctuations are observed in supersonic flames than in subsonic flames, and that strong reaction occurs in the upper part of the flames. Driscoll et al. [13] identified the various factors that affect the flame length in a confined combustor. They showed that the lengths of supersonic flames are shorter than those of subsonic flames at the same velocity ratio or at the same density ratio, and that the flame lengths decrease as $U_{F} \rho_{F} /$ $U_{A} \rho_{A}$ increases. Bryant et al. [14] investigated the detailed fl ame structures of subsonic and supersonic flames by using $\mathrm{OH}$ PLIF images in a confined combustor. They found that the $\mathrm{OH}$ signal is concentrated at the downstream side of the supersonic flames, and the high strain rates play an important role in fuel-air mixing at the base of the flames. However, it was impossible to avoid the influence of shock waves generated by the change in the cross-sectional area of the confined supersonic combustor.

The detailed flame structures and the modes of bluffbody stabilized flames in supersonic ranges are not clearly understood. We investigated the structures of unconfined hydrogen diffusion flames in a supersonic coflow of air $(M=1.8)$. The objectives of this study were to define the stability limits of high-speed hydrogen flames and to investigate the structure of hydrogen diffusion flames behind a bluff body in an unconfined combustor as the coflow air velocity is increased from subsonic to supersonic regimes.

\section{Experiments and Analysis Methods}

\subsection{Supersonic Combustor and Conditions}

Figure 1 shows a small-scale supersonic combustor. The supersonic air nozzle was designed by the characteristic method and manufactured, so that the expansion ratio of the supersonic air nozzle $\left(A_{e} / A^{*}\right)$ was 1.438. The design Mach 


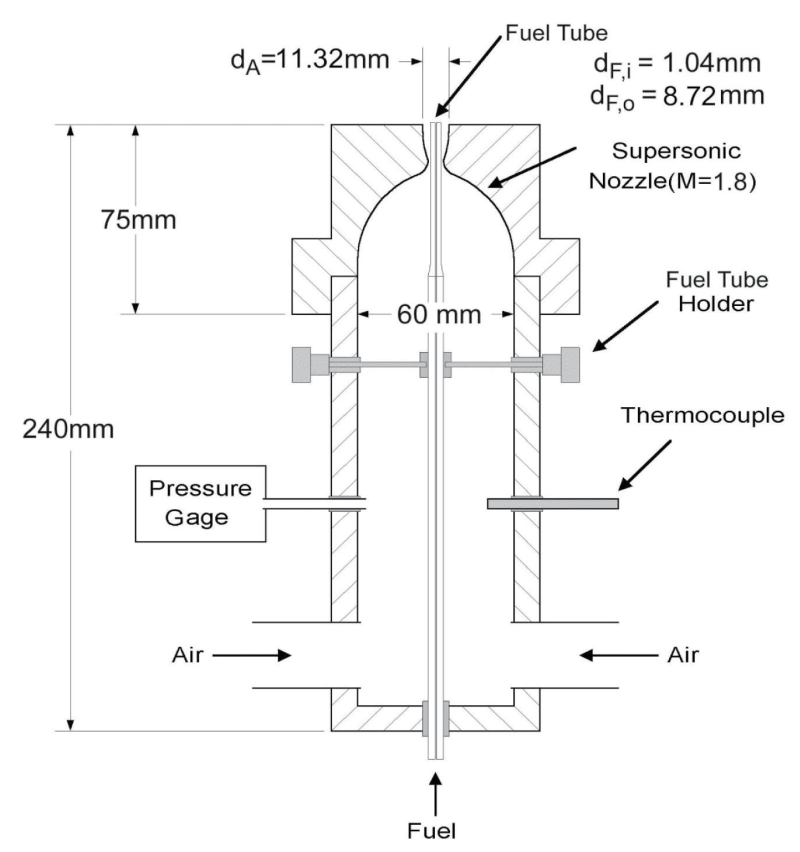

Fig. 1. Schematic of bluff-body combustor for hydrogen-air diffusion flames $(B R=0.60)$.

number of the supersonic combustor was 1.8. The fuel tube had an inner diameter $\left(d_{F, i}\right)$ of $1.04 \mathrm{~mm}$, an outer diameter $\left(d_{F, o}\right)$ of $8.72 \mathrm{~mm}$, and a length of $37 \mathrm{~cm}$. The fuel velocity profile was assumed to be a fully developed pipe flow. The velocity of hydrogen gas was changed from zero to the sonic velocity. The fuel mass flow rate was monitored with a calibrated choked orifice (diameter $=0.4 \mathrm{~mm}$ ).

Fuel tubes with a thick lip were used to stabilize supersonic flames, because a thick tube lip acts as a bluff body and defines the size of the recirculation zone, as shown in Fig. 2. With a fixed inner tube diameter $\left(d_{F, i}\right)$ and the same air flow exit area, a thicker fuel tube would extend the stability ranges of the fuel and air velocities [15]. The dimensions of fuel tubes and air nozzles are shown in Table 1. The blockage ratio could be changed from 0.50 to 0.64 . The flames could be stabilized in the supersonic coflow condition $(M=1.8)$ when the blockage ratio $\left(d_{F, o}{ }^{2} / d A^{2}\right)$ was larger than 0.45 .

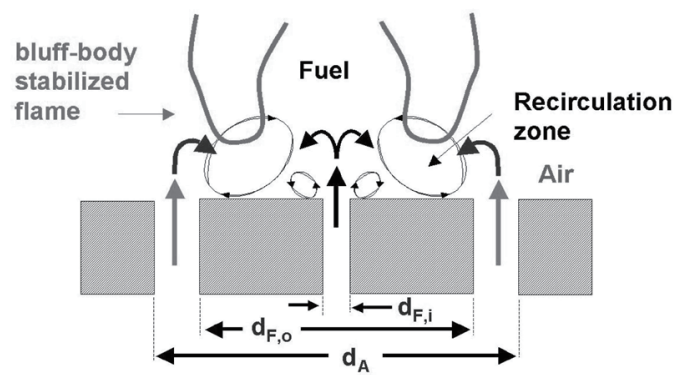

Fig. 2 Formation of bluff-body stabilized flame; Blockage ratio $(B R)=$ $d F, O 2 / d A 2$.
Table 1. Dimensions of fuel tubes and air nozzles at each blockage ratio. Inner diameter of fuel tube and exit areas of coflow air are fixed $\left(d_{F, i}=1.04 \mathrm{~mm}, \pi\left(d_{A}^{2}-d_{F, 0}{ }^{2}\right) / 4=40.8 \mathrm{~mm}^{2}\right)$.

\begin{tabular}{cccc}
\hline $\begin{array}{c}\text { blockage ratio } \\
(B R), \\
\left(d_{F, 0} / d_{A}\right)^{2}\end{array}$ & $\begin{array}{c}\text { bluff-body } \\
\text { diameter, } \\
d_{F, 0}[\mathrm{~mm}]\end{array}$ & $\begin{array}{c}\text { diameter of air } \\
\text { nozzle, } \\
d_{A}[\mathrm{~mm}]\end{array}$ & $\begin{array}{c}\text { lip thickness of fuel } \\
\text { nozzle, } \\
\left(d_{F, 0}-d_{F, i}\right) / 2[\mathrm{~mm}]\end{array}$ \\
\hline 0.50 & 7.14 & 10.14 & 3.05 \\
0.55 & 7.92 & 10.72 & 3.44 \\
0.60 & 8.74 & 11.32 & 3.85 \\
0.64 & 9.52 & 11.94 & 4.24 \\
\hline
\end{tabular}

To investigate the effects of coflow velocity on the structure of hydrogen flame, we varied the air velocity from subsonic to supersonic conditions. The mass flow rate or the momentum flux can be used as a parameter when defining the flame types and analyzing the flame stability, but velocity is generally adopted in the analysis of characteristic modes of bluff-body stabilized flames in the subsonic range $[5,6,16$, 17]. However, the actual velocity of air at a given condition cannot be varied, even though the supply of air mass flow rate can be increased, because the area ratio of the throat to the exit and the stagnation temperature are fixed in the supersonic nozzle of the combustor, and consequently, the exit Mach number of the combustor is fixed to 1.8. Thus, it is convenient to introduce a mass-weighted velocity that is proportional to the mass flow rate of the flow.

The mass-weighted velocity is directly proportional to the measured mass flow rate of the mass flux, as shown in Eqns. (1) and (2). The mass-weighted velocities of air and fuel $\left(U_{m, A}, U_{m, F}\right)$ are defined by

$$
\begin{aligned}
& U_{m, A}=\rho_{\mathrm{A}} U_{A} / \rho_{A, \text { ref }}=\dot{m}_{A} /\left(\rho_{A, \text { ref }} A_{A}\right) \\
& U_{m, F}=\rho_{F} U_{F} / \rho_{F, \text { ref }}=\dot{m}_{F} /\left(\rho_{F, \text { ref }} A_{F}\right)
\end{aligned}
$$

These are defined as the value of the mass flux divided by the gas density at standard conditions: $T=294 \mathrm{~K}, P=1 \mathrm{~atm}$. In these conditions, $\rho_{A, \text { ref }}$ and $\rho_{F \text { ref }}$ have values of 1.225 and $0.08527 \mathrm{~kg} / \mathrm{m} 3$, respectively. The mass fluxes $\left(\rho_{A} U_{A}, \rho_{F} U_{F}\right)$ can be obtained by dividing the mass flow rates by the crosssectional areas of the fuel tube and air stream at the fuel exit plane. $\mathrm{m} A_{A}$ and $\mathrm{m} A_{F}$ are the measured mass flow rates of fuel and air. A_A and A_F are the cross-sectional areas of the fuel tube and air stream at the fuel exit plane.

The values of the mass-weighted velocity in the subsonic range of $M<0.3$ are close to the absolute velocities of air and fuel, because the densities of air and fuel were not very different from those at the reference condition. Hence, the velocity of the flow in a low-Mach-number flow $(M<0.3)$ is directly proportional to the mass flow rate. However, in the supersonic ranges of this research, the velocity of the flow 
was fixed, although the mass flow rates were varied. This condition indicates that the densities of air and fuel are varied by the mass flow rates; the density in the supersonic range is varied by the mass flow rate. Since our results show the flame modes in a broad velocity range from subsonic to supersonic, the mass-weighted velocity is useful. The mass-weighted velocity means the actual velocity at the lowvelocity condition $(M<0.3)$. However, the mass-weighted velocity increases because the density of the air and fuel (or mass flux) increases in the supersonic range, because the exit Mach number (or exit velocity) is fixed [15].

\subsection{Numerical methods}

The axisymmetric Navier-Stokes equation for multiple species was employed to analyze the mixing of hydrogen fuel with coflow air. The conservation form of the governing equations including balance equations for $\mathrm{N}$ species may be written as follows:

$$
\frac{\partial \mathbf{Q}}{\partial t}+\frac{\partial \mathbf{F}}{\partial x}+\frac{\partial \mathbf{G}}{\partial y}+\mathbf{H}=\frac{\partial \mathbf{F}_{\mathbf{v}}}{\partial x}+\frac{\partial \mathbf{G}_{\mathbf{v}}}{\partial y}+\mathbf{H}_{\mathbf{v}}
$$

In this expression, $\mathbf{Q}$ is a conservative variable; $\mathbf{F}$ and $\mathbf{G}$ are convective fluxes; $\mathbf{F}_{\mathbf{v}}$ and $\mathbf{G}_{\mathbf{v}}$ represent diffusion fluxes; and $\mathbf{H}$ and $\mathbf{H}_{\mathbf{v}}$ correspond to source terms associated with cylindrical coordinates. The details of the governing equations and thermal properties are described elsewhere [18]. Roe's FDS (Flux Difference Splitting) method and MUSCL (Monotone Upstream-Centered Schemes for Conservation Laws) scheme are used to solve multi-species equations. Diffusion flux terms are discretized by the central difference scheme. LU-SGS (Lower Upper-Symmetric Gauss Seidel) method is used as a fully implicit time integration method for the analysis of supersonic reacting flows. Menter's SST (Shear Stress Transport) model [19] is used as a turbulence model. The numerical algorithm developed in the present study was validated with experimental cases, such as cases of shockinduced combustion phenomena around a blunt body and shock/boundary layer interaction problems [20].

In the simulation, the grid resolution was $160 \times 150$. A noslip boundary condition was used at the bluff body. The grid independence was tested with finer grid sizes. The selected grid size was fine enough to resolve the qualitative trends without the loss of detailed information obtained with the use of finer grid sizes. In this non-reacting condition, the mixing of fuel jet and coflow air was studied numerically.

\subsection{OH PLIF Measurements}

$\mathrm{OH}$ PLIF was used to obtain spatially and temporally resolved images of the reaction zone within the supersonic combustor. The $\mathrm{OH}$ radical concentration increased rapidly around the flame in about $20 \mu \mathrm{sec}$ and then decomposed slowly in 1 to $5 \mathrm{~ms}$ by a 3-body recombination reaction [21]. Thus, supereqilibrium $\mathrm{OH}$ existed near the flame front. The $\mathrm{OH}$ radical, which is an intermediate product of a chemical reaction, reached a concentration of more than ten times that of the $\mathrm{O}$ or $\mathrm{H}$ radical [22]. Therefore, the $\mathrm{OH}$ radical emitted a more intensive fluorescence signal than the other species when laser light was absorbed. Hence, the fluorescence signal of $\mathrm{OH}$ radicals is widely used as an indicator of flame fronts in reacting flow studies.

For OH PLIF, an Nd:YAG-pumped dye laser was turned to the $\mathrm{Q}_{1}(6)$ transition of the $A^{2} \Sigma^{+} \leftarrow X^{2} \Pi\left(v^{\prime}=1, v^{\prime \prime}=0\right)$ band $(\lambda=282.94 \mathrm{~nm})$, and the fluorescence from the $A-X(1,0)$ and $(0,0)$ bands $(\lambda=306 \sim 320 \mathrm{~nm})$ were collected with a UVNikkor $105 \mathrm{~m} / \mathrm{f} 4.5$ lens. A $54 \times 36 \mathrm{~mm}$ region was focused onto the ICCD camera $(576 \times 384$ pixels). Two color glass filters (i.e. WG-305 and UG-11) were used to reject scattered light signals.

\section{Results And Discussions}

\subsection{Stability Curve of Bluff-body Stabilized Flames}

Figure 3 shows the flame stability curves of a bluff-body stabilized flame. There are two distinct lobes in the stability curve of this flame, and each lobe is affected by different physical parameters, such as the lip thickness of the fuel tube, coflow air temperature, and fuel or air velocities [15]. In the present research, the tips of the lobes were not closed due to the experimental limitation regarding the fuel and air flow rates. However, the shapes of these curves in the low velocity range are similar to those of Yoon et al. [15]. They found that two distinct limits were developed: the farfield blowout limit of a lifted flame (air-dominated regime), where the flame blows out after it lifts off, and the near-field blow out limit (fuel-dominated regime), where the flame blows out suddenly with no lift-off. Of the two types of limits, the near-field blowout limit is the focus of this study. The near-field limit in Fig. 3 occurred when the fuel flow rate was relatively small compared to the airflow rate, which is a typical operating condition in most propulsion devices. The near-field blowout limit can be extended farther for large air velocities if a thick fuel tube is used. However, this distinct lobe-shape was not observed in many previous studies that employed a fuel tube with a sharpened rim. The far-field blowout of lifted flames is not the primary interest of the present study, because it is impossible to obtain far-field 
blowout while supersonic air conditions are maintained.

In many studies, the air and fuel velocities are generally used as the variables of flame stability curves. The flame stability curves indicate the conditions and ranges for the existence of the flame, because the stable equilibrium position of the flame and the stability limit can be explained in terms of flame propagation velocity with respect to the gas velocity $[4,5,16,17]$. For supersonic flames with a fixed Mach number, the mass-weighted velocity of the mixture can be used to extend this stability curve to the supersonic range, because the actual velocity is not changed [15]. The usefulness of the mass-weighted velocities is explained in the description of Eqns. (1) and (2). The mass-weighted velocity does not coincide with the flow velocity itself. Thus, for clarity, we used the mass fluxes $\left(\rho_{A} U_{A}, \rho_{F} U_{F}\right)$ as well as the mass-weighted velocities and plotted these two parameters simultaneously, as shown in Fig. 3. Another important parameter can be the momentum flux $\left(\rho U^{2}\right)$, which may suitably describe the change of the flame length, because the amount of entrained air is proportional to this quantity. However, in compressible flows, the density is not fixed, and the local value cannot be obtained directly. The mass flux is often used instead of the momentum flux to characterize supersonic combustion phenomena [23, 24]. Driscoll et al. [13] used the mass flux ratio to predict the flame length in subsonic and supersonic flows, and showed that this ratio controls the flame length.

Figure 3 shows the stability curves of the bluff-body stabilized flame at each blockage ratio from 0.50 to 0.64 . The larger blockage ratio corresponds to the thicker lip of fuel tube, as shown in Table 1. The inner diameter of the

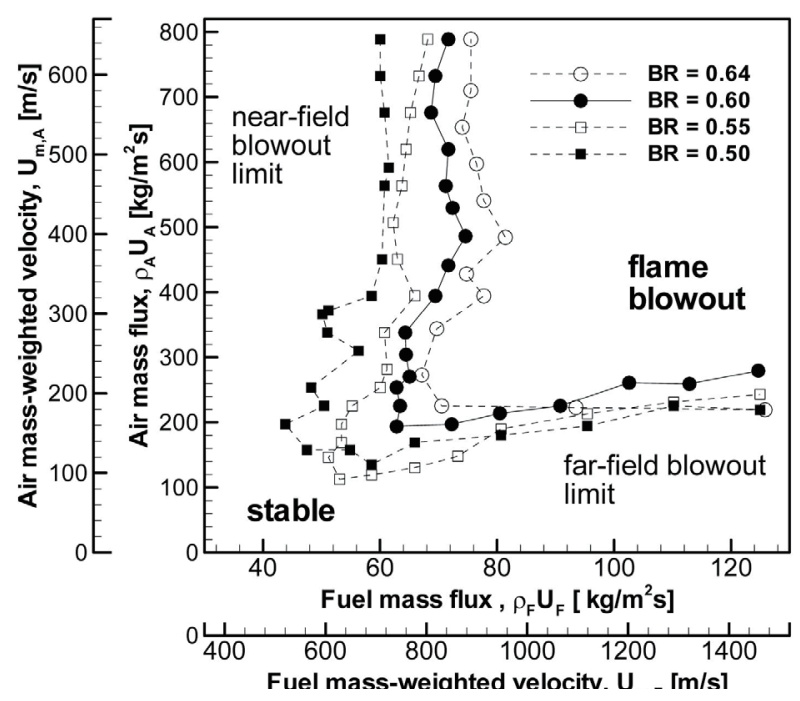

Fig. 3. Flame stability curves of bluff-body stabilized flames obtained by varying blockage ratio (the lip thickness of the fuel nozzle). fuel tube was fixed to maintain the same fuel jet condition in each case, but the outer diameter of the air nozzle was changed to increase the blockage ratio and to conserve the exit air flow area. Figure 3 indicates that stability was improved by increasing the lip thickness (or blockage ratio) of the fuel tube in the near-field blowout limit. The fuel tube with larger lip thickness acted as a bluff-body and provided a larger recirculation zone. This enlarged recirculation zone broadened the low speed region, and this broadening stabilized the flame. However, the far-field stability limit was not affected by the variation of the fuel tube lip thickness, because the central-jet dominated flames were slightly affected by the change of bluff-body size.

Figure 4 shows the stability limits of the global strain rates, which are the mass-weighted velocities normalized by bluff-body sizes, respectively (outer diameter of fuel nozzle, $\left.d_{F, o}\right)$, for the bluff-body stabilized non-premixed flame. The stability curves have an L-type shape, and the four curves of Fig. 3 collapse to a single line. Downstream of the bluffbody, the size of the recirculation zone is proportional to the lip thickness. Thus, the relationship between the flame residence time $\left(\tau_{R}\right)$ and the global strain rate based on the lip thickness can be obtained for the bluff-body stabilized flame:

$$
\begin{aligned}
& \text { global strain rate of air }=\frac{U_{m, A}}{d_{F, o}} \propto \frac{U_{m, A}}{L_{R Z}}=\left(\tau_{R, A}\right)^{-1} \\
& \text { global strain rate of fuel }=\frac{U_{m, F}}{d_{F, o}} \propto \frac{U_{m, F}}{L_{R Z}}=\left(\tau_{R, F}\right)^{-1}
\end{aligned}
$$

where $L_{R Z}$ is the length of the recirculation zone. The mass-weighted velocity is used instead of the actual velocity

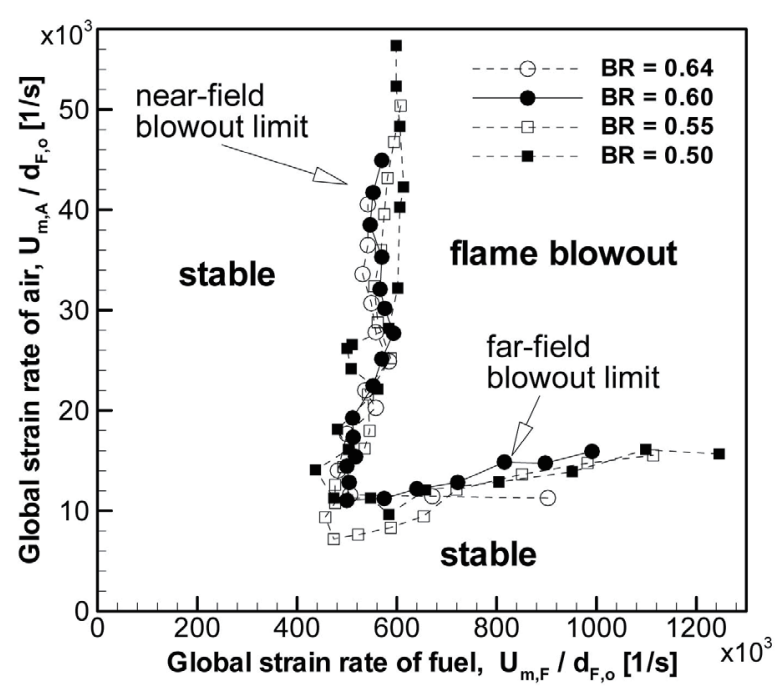

Fig. 4. Normalized stability curves by using the global strain rate. 
to extend this relation to the supersonic range. If the global residence time is defined as the time required for flow to cross the recirculation zones, the flame can be stabilized when the global residence time is large. From Fig. 4, the stability of the bluff-body flame is related to the global strain rate (or the global residence time), and the larger the fuel tube thickness, the greater the increase in the flame stability, because of a larger recirculation zone and the prolonged mixing of fuel and air.

\subsection{Combustion Diagram for Bluff-body Stabilized Flames}

Figure 5 shows a combustion diagram with different regimes for a bluff-body stabilized non-premixed flame. The blockage ratio of this flame is 0.60. $\gamma=\rho_{A} U_{A} / \rho_{F} U_{F}$ is defined as the mass flux ratio of air and fuel streams. This quantity is identical to the ratio of mass-weighted velocities $\left(\gamma=U_{m, A}\right)$ $\left.U_{m, F}\right)$. The classification used in Fig. 5 is based on the criteria of Chen et al. [6], who investigated flame regimes and stability curves of subsonic flames formed by LPG gas fuel. By varying the parameter $\gamma$, three characteristic stable flame modes can be found, as shown in Fig. 4 : jet-like flame (Regime I), central-jet dominated flame (Regime II), and recirculation zone flame (Regime III), which has an open-tip or closedtip. The typical flame shapes of cases I, II, IIIa and IIIb are shown as photographs, Schlieren images, $\mathrm{OH}$ PLIF images, and simulation results in Figs. 7 and 8. The $\gamma_{u}$ limit (triangle symbol) is $Y_{H 2}$ the border line between Regimes II and III, and the $\gamma_{1}$ limit (inverse triangle symbol) is at the border line between Regimes I and II. In the present study, the values of $\gamma_{u}$ limit and $\gamma_{1}$ limit are about 0.2 and 0.006 , respectively. The $\gamma_{u}$ value was measured accurately, but the $\gamma_{1}$ value was drawn approximately to show the transition between Regimes I and II. The shapes of the combustion diagrams for the other three bluff bodies are qualitatively similar to each other. The general trends, which are shown in Fig. 5, are consistent with those of previously proposed diagrams $[5,6]$, and are useful for identifying the combustion mechanism of bluff-body stabilized hydrogen flames, which are obtained for a wide range of coflow air velocity from zero to supersonic.

Generally, hydrogen/air flames have a large laminar burning velocity, because such mixtures have a short induction time and large heat release values. Thus, hydrogen flames can be maintained for a wider range of velocities up to supersonic conditions than hydrocarbon fueled flames $[4,6]$. In the present study, the flame stabilization at higher flow velocity was attributed to the high blockage ratio and energetic hydrogen fuel. When the fuel jet has much higher momentum (Regime I), the central fuel jet penetrates

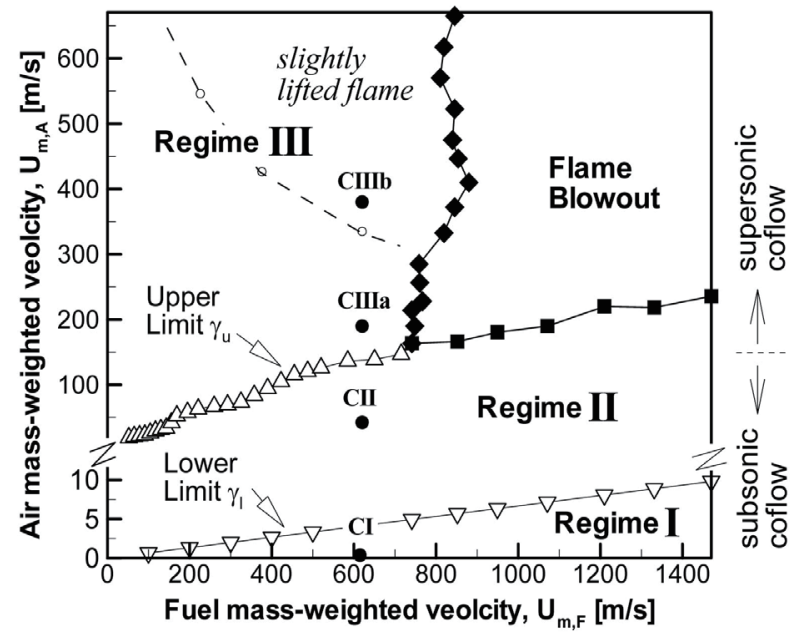

Fig. 5. Combustion diagram of bluff-body stabilized flames: jet-like flame (Regime I), central jet-dominated flame (Regime II), and recirculation zone flame (Regime III). The $\gamma_{-} u$ limit and $\gamma_{-} 1$ limit are about 0.2 and 0.006 , respectively. The conditions of case $\mathrm{I} \sim \mathrm{II} \mathrm{b}$ are denoted as $\mathrm{Cl}(\bullet) \sim \mathrm{Cl} \mathrm{lb}(\bullet)$.

through the recirculation bubble. When the fuel jet and annular air momentums are similar to each other (Regime II), a central-jet dominated flame can develop. This flame mode is characterized as a narrow-waist flame. When the fuel jet momentum is too weak to penetrate the recirculation bubble (Regime III), all fuel mass or most of the fuel mass will be retained behind the bluff body to form a recirculation zone flame. More specifically, Regime III was divided into two modes: open-tip flame and closed-tip flame.

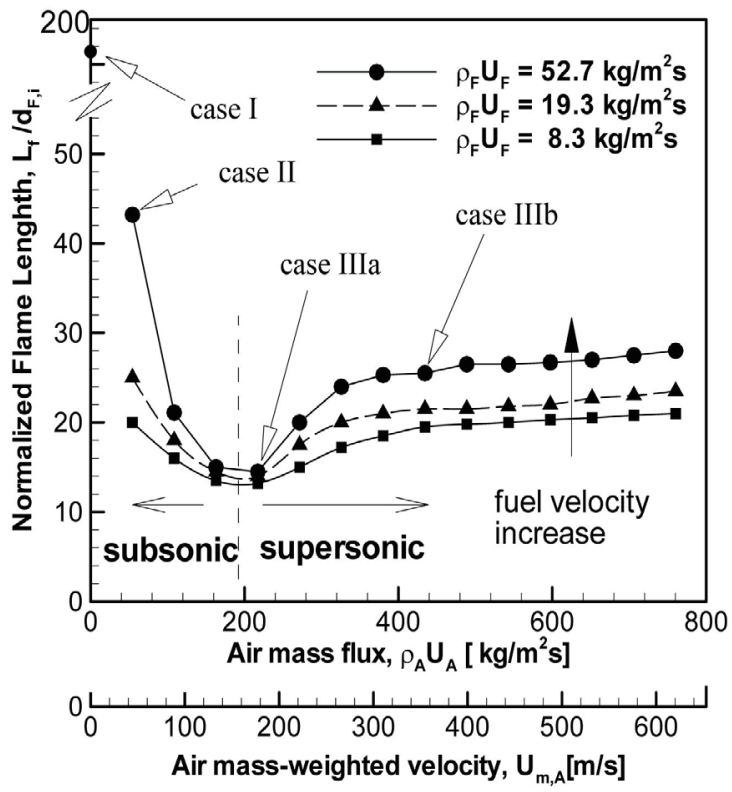

Fig. 6. Effect of coflow air on the length of hydrogen diffusion flames. For all cases I $\sim 11 \mathrm{~b}$, the fuel mass flux (p_F U_F) is fixed to 52.7 $\mathrm{kg} / \mathrm{m}^{2} \mathrm{~s}$. 


\subsection{Effect of Coflow on Supersonic Flames}

The visible length of the supersonic flame is the measure of the fuel-air mixing rate, which affects the flame stability process. Rapid mixing produces a short flame. A long flame has stoichiometric contours further downstream, with reduced strain rates. Figure 6 shows the variation of flame length according to the increase in the air mass flux. The flame length normalized by the inner diameter of fuel tube $\left(d_{F, i}\right)$ is plotted with respect to the air mass flux and the massweighted velocity. For the different fuel flow conditions of $8.3,19.3$, and $52.7 \mathrm{~kg} / \mathrm{m}^{2} \mathrm{~s}$, similar trends were found. At all fuel velocities, flame lengths have minimum values at the same air velocity $\rho_{A} U_{A}=200 \mathrm{~kg} / \mathrm{m}^{2} \mathrm{~s}$, which is near the transition condition from subsonic to supersonic.

In the subsonic coflow ranges, the flame length decreases with increasing air mass flux. This decrease was due to the increased mixing by a small quantity of the high-velocity fuel penetrating the center of the recirculation region. However, in the supersonic ranges, the flame length increases slowly and then eventually reaches a near-constant value. This phenomenon was attributed to the air-entrainment of subsonic flow and the compressibility effect of supersonic flow, which will be explained by the results of the mixing simulations.
To investigate the flame structures with the change of air velocity, we fixed the hydrogen fuel mass flux at $52.7 \mathrm{~kg} /$ $\mathrm{m}^{2} \mathrm{~s}$, and the Reynolds number of fuel was about 6,000 . The detailed operating conditions are given in Table 2 and are indicated in Fig. 7 for cases I, II, IIIa and IIIb, respectively. These conditions represent the typical characteristics of each type of flame. Different visualization methods were used to analyze the structure of these flames.

Case I is the pure diffusion flame, which has no coflow air, as shown in Fig. 7a. Its OH PLIF image indicates that the reaction zone was established along the shear layer between the fuel jet and ambient air. As the air mass flux was increased slowly from zero to the value near the condition of case II, the flame shape was changed to the narrow-waist shape, as shown in Fig. 7b. At the narrow waist of the flame, a high strain rate zone was created by the strong entrainment of high-momentum coflow air. The highly strained zone decreased the reaction rates and local extinction thus occurred. The $\mathrm{OH}$ radical image marks a concentrated region along the boundaries between the fuel and air, and indicates a local extinction in the narrow waist of the flame (at $x / d_{F, i}=12$ ).

When the air-fuel mass flux ratio $\gamma$ exceeded 0.2 , the jetdominated flame of Regime II was changed to a recirculation zone flame of Regime III, as shown in Fig. 7c. When the air

Table 2. Experimental conditions of coflow air at the exit plane of the supersonic combustor having a bluff-body $\left(B R=0.60, d_{F, i}=1.04 \mathrm{~mm}, d_{F, 0}=8.72\right.$ $\left.\mathrm{mm}, d_{A}=11.32 \mathrm{~mm}\right)$ with a fixed hydrogen fuel condition $\left(\rho_{F} U_{F}=52.7 \mathrm{~kg} / \mathrm{m}^{2} \mathrm{~s}, U_{m, F}=620 \mathrm{~m} / \mathrm{s}, R e=6000, T_{0, F}=294 \mathrm{~K}\right)$.

\begin{tabular}{|c|c|c|c|c|}
\hline & case I & case II & case IIIa & case IIIb \\
\hline $\begin{array}{c}\text { total pressure of air } \\
{[\mathrm{atm}]}\end{array}$ & - & 1.34 & 2.36 & 3.72 \\
\hline air mass flux $\left[\mathrm{kg} / \mathrm{m}^{2} \mathrm{~s}\right]$ & - & 56.4 & 223.0 & 446.1 \\
\hline $\begin{array}{l}\text { air mass-weighted } \\
\text { velocity }[\mathrm{m} / \mathrm{s}]\end{array}$ & - & 46.0 & 182.1 & 364.1 \\
\hline air velocity $[\mathrm{m} / \mathrm{s}]$ & - & 42.5 & 486.8 & 486.8 \\
\hline $\begin{array}{l}\text { coflow } \\
\text { condition }\end{array}$ & no coflow air & $\begin{array}{l}\text { subsonic } \\
\text { coflow air }\end{array}$ & $\begin{array}{l}\text { near sonic } \\
\text { coflow air }\end{array}$ & $\begin{array}{l}\text { supersonic } \\
\text { coflow air }\end{array}$ \\
\hline $\begin{array}{l}\text { classification } \\
\text { of flame }\end{array}$ & $\begin{array}{l}\text { jet-like flame } \\
\text { (Regime I) }\end{array}$ & $\begin{array}{c}\text { central jet } \\
\text { dominated flame } \\
\text { (Regime II) }\end{array}$ & $\begin{array}{l}\text { transient } \\
\text { recirculation } \\
\text { zone flame } \\
\text { (Regime III) }\end{array}$ & $\begin{array}{c}\text { recirculation } \\
\text { zone flame } \\
\text { (Regime III) }\end{array}$ \\
\hline flame type & $\begin{array}{l}\text { pure diffusion } \\
\text { flame }\end{array}$ & $\begin{array}{l}\text { narrow-waist } \\
\text { flame }\end{array}$ & $\begin{array}{l}\text { open-tip } \\
\text { flame }\end{array}$ & $\begin{array}{l}\text { closed-tip } \\
\text { flame }\end{array}$ \\
\hline
\end{tabular}




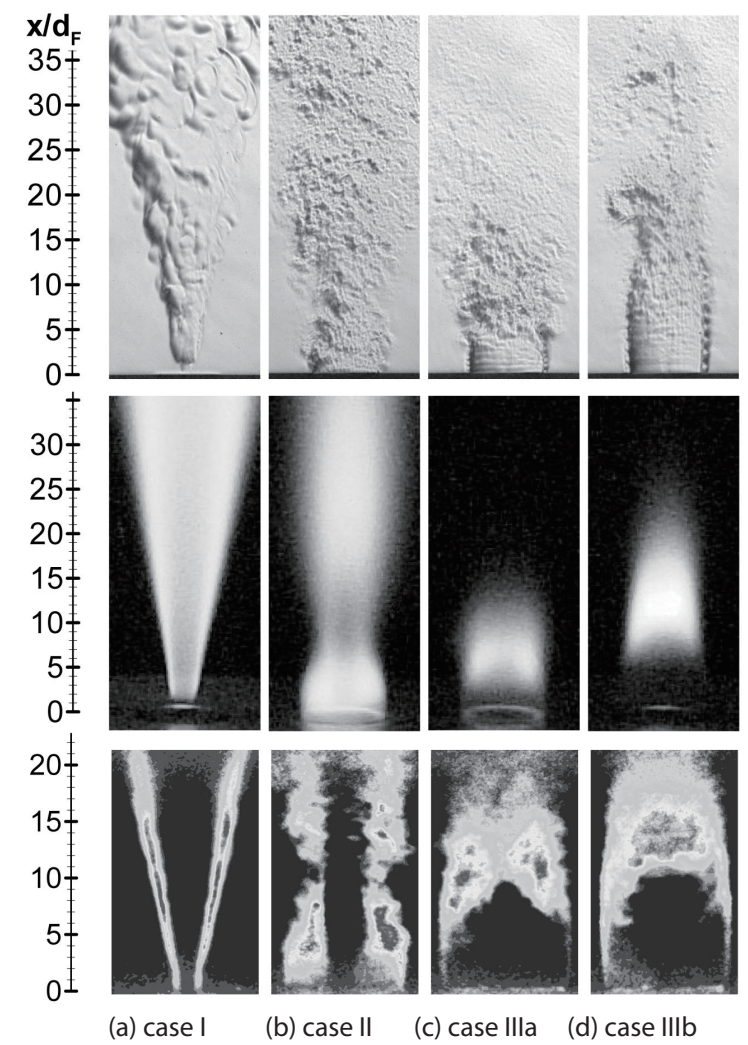

Fig. 7. Typical images of four stable modes of $\mathrm{H} 2$ diffusion flames with the blockage ratio of 0.60 . Schlieren images (top, exposure time $=1 \mu \mathrm{sec}$ ), direct photographs (middle, exposure time $=0.5 \mathrm{~s}$ ), and OH PLIF images (bottom): (a) jet-like flame (b) central-jet dominated flame (c) recirculation zone flame jet with open-tip and (d) recirculation zone flame jet with closed-tip.

mass flux was increased to that of case IIIa and the subsonic flames were changed to supersonic flames, the flame started to shrink and finally became extinct in the upper part of the narrow waist. This phenomenon is attributed to the large amount of air entrained towards the flame. In the condition of case IIIa, the flame had the shortest length and an open-tip shape, as shown in the OH PLIF images. In this case, the stagnation point was formed just downstream of the recirculation zone, but the jet penetrated the recirculation zone intermittently. Thus, case IIIa was classified as a transient recirculation zone flame, because the characteristics of the central jet-dominated flame remained.

As the airflow velocity is further increased, as shown in case IIIb for the supersonic flame, the flame became longer and thinner with a closed-tip shape, as shown in Fig. $7 \mathrm{~d}$. The high intensity region of the $\mathrm{OH}$ radicals moved from the vicinity of the recirculation zone to the center of the flame, because the centerline stagnation point may have acted as an effective source of fuel. The anchoring point of this supersonic flame was at the outer edge of the outside recirculation zone near the exit of the bluff-body fuel tube, as suggested by others $[25,26]$, and the actual reaction occurred at the end position of shock structure, as shown in the Schlieren image and photograph in Fig. $7 \mathrm{~d}$.

The supersonic flame is slightly lifted in case IIIb. A flame lifts off when there is an imbalance between flame propagation and an opposing fuel flow [11]. In this study, the flame lifted at a higher air velocity $\left(U_{m, A}>300 \mathrm{~m} / \mathrm{s}\right)$ due to the high burning velocity of the hydrogen fuel. Also, for the supersonic condition, compressibility seemed to have some additional effects on the slightly lifted flame, because the over-expanded shock structure established in the flow was found near the flame anchoring region, as shown in Fig. 7d.

\subsection{Simulation of Fuel-Air Mixing}

Non-reacting simulations were not sufficient for the prediction of reacting flow phenomena, because the interaction between combustion and aerodynamics was not considered. Despite this limitation, we used non-reacting simulation results as supplementary data for understanding the flow characteristics near the fuel tube exit.

Figure 8 shows the simulation result of the mixing of hydrogen jet and coflow air, which did not chemically react. The top figures in Fig. 8 show pressure contours (dashed lines) and streamlines (solid lines). The bottom figures show hydrogen mass fraction contours (thin solid lines) and the stoichiometric line (thick dashed line) of $Y_{\mathrm{H} 2}=0.0287$. As the coflow air was entrained to the fuel jet, the hydrogen fuel was mixed with air, and then a 'partially premixed zone' was formed.
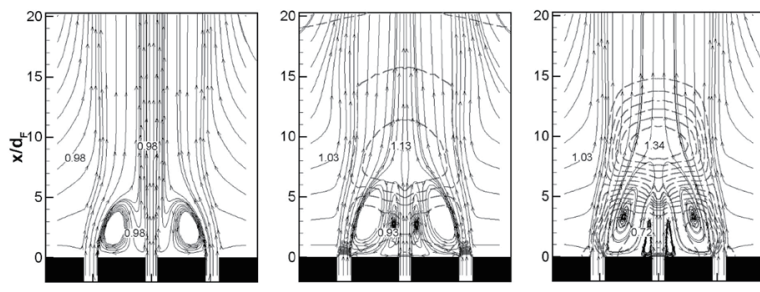

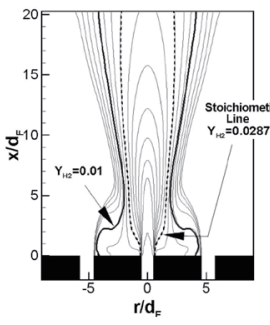

(a) case II

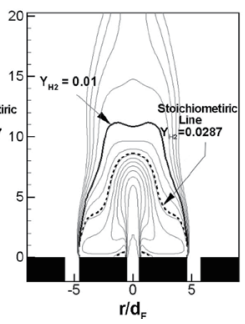

(b) case IIIa

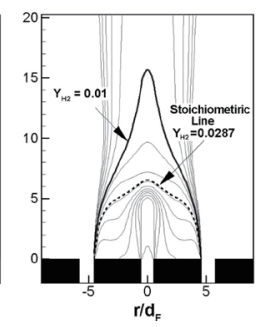

(c) case IIIb
Fig. 8. Simulation of $\mathrm{H}_{2}$-air mixing of non-reacting flows for cases II, IIla and IIlb: streamline and pressure contour (top) and fuel mass fraction and stoichiometric line (bottom). The expectedflame regions are defined as the areas between the stoichiometric line and $1 \%$ mass fraction line. 
To predict the possible flame location with the $\mathrm{OH}$ radical region, we defined the expected-flame region as the area between the $1 \%$ hydrogen mass fraction contour $\left(Y_{H 2}=0.01\right)$ and stoichiometric line $\left(Y_{H 2}=0.0287\right)$ obtained from the simulation. As Donbar et al. [27] showed through simultaneous images of $\mathrm{CH}$ radicals and $\mathrm{OH}$ radicals, a thicker $\mathrm{OH}$ layer existed at the fuel lean side, and the thinner $\mathrm{CH}$ layer was located on the fuel rich side. Thus, our estimation is valid in that the $\mathrm{OH}$ radical zone existed on the fuel lean side. Even though this result is obtained for the nonreacting case, the expected-flame regions agree well with the actual flame shape in the direct photographs, and with the reactive region in $\mathrm{OH}$ LIF images in Fig. 7 . The narrow waist was found in the subsonic case II, and the locations of the reactive zone were moved from the outside (case IIIa) to the center (case IIIb).

In case II of Fig. 8a, the coflow air jet with relatively small momentum moved toward the centerline along the outer stream of the recirculation zone, and then the coflow air abruptly changed its direction when it met the fuel jet. This directional change may cause a large strain rate at this point, inducing a flame waist. Consequently, this high strain rate almost extinguished the flame locally and thereby reduced the reaction rate.

The pressure field in case II was relatively uniform throughout the flame zone, whereas those of cases IIIa and IIIb varied. The low pressure zone (0.72 0.93 atm) existed near the fuel nozzle exhaust (cf. Fig. 8b), whereas the relatively high pressure zone (1.34 1.13 atm) was located on the downstream side of the recirculation zone. The fuel jet expanded abruptly as it passed through the lowpressure zone and then lost its momentum by the blockage of the high-pressure zone. Thus, the fuel jet may follow the border of the recirculation zone without crossing the highpressure zone. Hence, the fuel jet had more time to mix with the air entrained along the recirculation zone. Due to the increased mixing time, the partially premixed zone was formed downstream of the center stagnation point. This is believed to explain the formation of partially premixed flame characteristics observed in cases IIIa and IIIb. An increase in the coflow air momentum tended to augment the size of the recirculation zone, where the flame can be stabilized in the supersonic airflow, as illustrated in Fig. 8.

As shown in Figs. $8 \mathrm{~b}$ and $8 \mathrm{c}$, the extent occupied by the stoichiometric line in case IIIb is reduced more that in case IIIa, but the vertical position of the $1 \%$ line $\left(Y_{H 2}=0.01\right)$ is slightly increased at the center of the fuel nozzle. Thus, the height of the partially premixed zone was increased with the air mass flow rate. This explains the elongation of the visible flame, as shown in Fig. 7, and the downstream movement of the $\mathrm{OH}$ radical core region. It is interesting to note the shape of the estimated flame contours in cases IIIa and IIIb. The flat top shape in case IIIa (Fig. 8b) changes to a steep and sharp top shape as in case IIIb (Fig. 8c). This evolution may explain the transition from the open-tip flame to the closedtip flame.

These expected-flame regions explain the abrupt decrease in the subsonic flame length and the slow increase in the supersonic flame length. In the subsonic coflow range, coflow air was entrained to the fuel jet and the mixing of fuel and air was enhanced, and thus, the flame length was reduced with increasing air mass flux. However, once the air coflow reached the supersonic coflow air condition, mixing became independent of the amount of entrained air, but it was mainly controlled by increased compressibility effects. Thus, the partially premixed zone was located further downstream from the fuel nozzle, and finally, the flame was elongated due to the limited mixing.

\subsection{Structure of Supersonic Flames}

The recirculation zone flame can exist in both subsonic and supersonic coflow conditions. However, the flames corresponding to these two conditions are different. Figure 9 shows the subsonic and supersonic flames at the same air-to-fuel mass flux ratio $(\gamma=0.6)$, which corresponds to the recirculation zone flame condition. Although both flames were similar, the locations of highly reactive layers corresponding to subsonic and supersonic flow conditions were different. In the subsonic case, the chemical reaction mainly occurred around the outer shear layer of the downstream recirculation zone, whereas in the supersonic

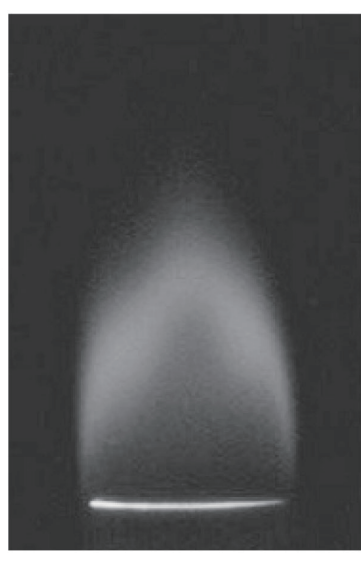

(a) subsonic air condition

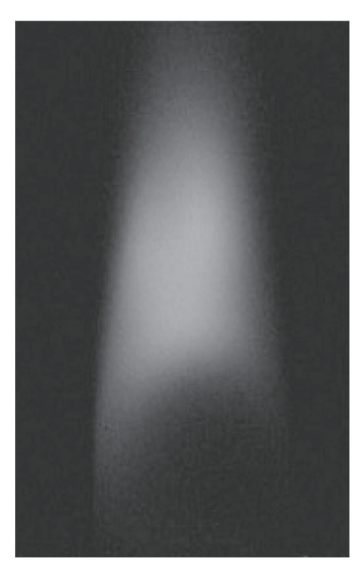

(b) supersonic air condition
Fig.9. Direct photographs of subsonic flame and supersonic flame at the same air to fuel mass flux ratio $(\gamma=0.6)$ : both flames are classified as recirculation zone flames. 
case, the reaction core was moved downstream of the center stagnation point. Recent LDV and OH PLIF measurements $[9,10]$ on flames stabilized on bluff-bodies in subsonic flow conditions showed that the main reaction zone exists at the outer shear layer of the air-driven vortex.

To find the fuel jet trajectory experimentally, we obtained scattering images for non-reacting flow by illuminating the flow with a planar laser sheet. Particles $\left(\mathrm{TiO}_{2}\right)$ are seeded in the fuel flow. Figure 10a is an instantaneous image taken with an Nd:YAG laser, and Fig. 10b is a long-exposure image taken with an Ar-ion laser. These two images indicate that a low scattering zone existed on the downstream side of the fuel jet. The trajectory of fuel observed in these pictures was

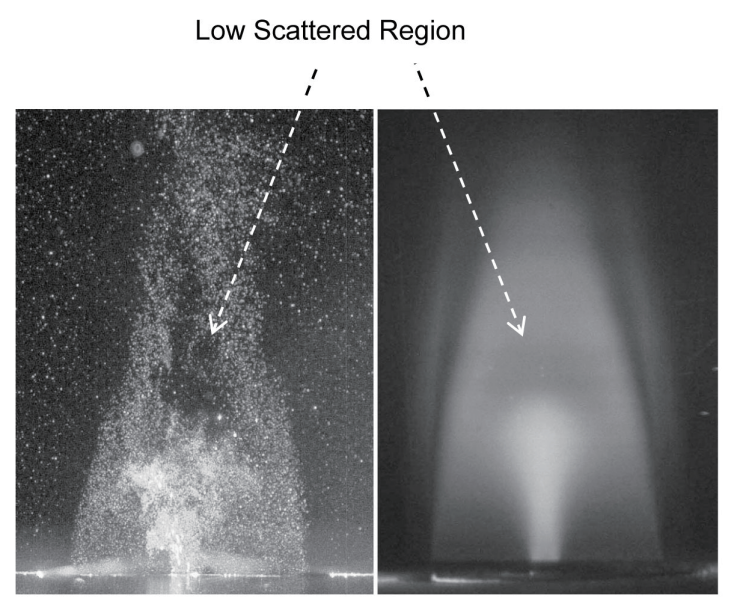

(a)

(b)

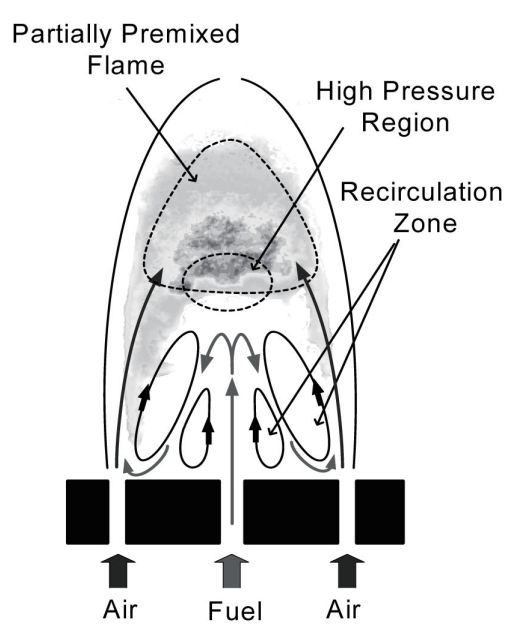

(c)

Fig.10. Near-field structure of flame with $M=1.8$ coflow air (case IIIb). Scattering images for non-reacting flows are obtained by sheet beam of laser when only fuel is injected: (a) instantaneous image by Nd:YAG Laser, (b) long time exposure image by Ar-ion Laser, and (c) schematic of supersonic flame structure, which is based on the OH PLIF images, scattering images and mixing simulations. similar to that obtained from the simulation shown in Fig. 8c. Using the direct photographs, Schlieren photographs, $\mathrm{OH}$ PLIF images and numerical simulation, we can construct a schematic representation of the supersonic flame structure, as shown in Fig. 10c.

The most noticeable characteristic of supersonic flames is the partially premixed zone on the downstream side of the stagnation point. Partially premixed flames are expected to form behind the bluff-body [1]. The fuel jet is blocked by the high-pressure zone and loses its momentum, and thus circulates through the recirculation zone. Finally, a partially premixed zone can exist at the flame center, because relatively longer fuel-air mixing time is available in supersonic flames. A reacting core is also found at the flame center, and a short flame length is obtained by the longer mixing time within the partially premixed zone. This mixing and the reaction processes are illustrated in Fig. 10c in the flame with supersonic coflow air. A reacting core is found at the flame center, and features characteristics of a partially premixed flame. This reacting core suggests that the flame structures may differ from that of a subsonic flame.

\section{Conclusions}

We investigated the structure of bluff-body stabilized hydrogen flame with high-speed coflow air varying from subsonic to supersonic velocities of up to Mach 1.8. Stability curves were plotted to find the blowout regimes. The flame blowout stability was improved by the use of a thicker fuel tube, which works like a bluff-body. When the global strain rate was defined as mass-weighted velocity normalized by the bluff-body size, each stability curve collapsed to a single line. This collapse means that the flame stability was related to the global residence time (inverse of the global strain rate) of the flow in the stabilized flame. The flame stabilization modes were classified into three regimes: (i) jet-like flame, (ii) jet dominated flame, and (iii) recirculation zone flame. The upper and lower limits of air-fuel mass flux ratios $\left(\gamma_{u}, \gamma_{l}\right)$ were used to distinguish the flame modes.

The flame length changed independently of the fuel mass flux. The minimum flame length was observed at the same air mass flux condition of $200 \mathrm{~kg} / \mathrm{m}^{2} \mathrm{~s}$, which was similar to the transition condition from subsonic to supersonic speed. The subsonic flame length decreased with increasing air mass flux, whereas the supersonic flame length increased with air mass flux and finally reached certain value limits. When the coflow was in the subsonic ranges, air was entrained into the fuel jet and the mixing of fuel and air increased. Hence, the flame length reduced with increasing air mass flux. However, 
once the air coflow reached supersonic conditions, mixing did not depend on the entrained air, but was controlled by the increased compressibility effect.

The structures of the flames were illustrated by various means, including direct photographs, Schlieren photographs, Mie scattering and OH PLIF images. OH PLIF images of the recirculation zone flame with supersonic coflow showed that the reaction zone existed on the downstream side of the recirculation zone. However, in the central-jet dominated flame having subsonic coflow, the reaction zone existed on the inner side of the recirculation zone. The recirculation zone flames of Regime III could also be divided into two modes: open-tip flame and closed-tip flame. The opentip flame became a closed-tip flame when the coflow air increased, which is believed to be related to the increased compressibility effects.

Fuel mass fraction contours were deduced from each case of the non-reacting flow simulation. The expected-flame region was defined as the area between the stoichiometric line and the $1 \%$ mass fraction of hydrogen obtained from numerical simulation. This region coincided well with the regions of $\mathrm{OH}$ radicals obtained by PLIF imaging. From the expected-flame region of the supersonic coflow condition (case IIIb), the location of the partially premixed zone was predicted, and a reacting core was expected in the supersonic flame.

In the closed-tip recirculation zone flame (supersonic flame), the fuel jet lost its momentum because of the high-pressure zone, and the fuel jet developed along the recirculation zone. The fuel had more time to mix. This increased mixing time may have produced the partially premixed flames rather than non-premixed flames. The blockage of the fuel jet and the formation of the partially premixed zone were confirmed by laser light scattering images and simulation results.

\section{Acknowledgement}

This work was supported by the Mid-career Researcher Program through an NRF grant funded by the MEST (049820110009), contracted through the Institute of Advanced Aerospace Technology at Seoul National University.

\section{References}

[1] Esquiva-Dano, I., Nguyen, H. T., and Escudie, D., "Influence of a bluff-body's shape on the stabilization regime of non-premixed flames", Combustion and Flame, Vol. 127,
2001, pp. 2167-2180.

[2] Kundu, K.M., Banerjee, D., and Bhaduri, D., “On flame stabilization by bluff-bodies", Journal of Engineering for Power, Vol. 102, 1980, pp. 209-214.

[3] Roquemore, W.M., Britton, R.L. and Sandhu, S.S., "Dynamic behavior of a bluff-body diffusion flame", AIAA Journal, Vol. 21, 1983, pp. 1410-1417.

[4] Masri, A.R., and Bilger, R.W., "Turbulent Diffusion Flames of Hydrocarbon Fuels Stabilized on a Bluff Body", Proceedings of the Combustion Institute, Vol. 20, 1984, pp. 319-326.

[5] Huang, R. F. and Lin, C. L., "Characteristic modes and thermal structure of nonpremixed circular-disc stabilized flame", Combustion Science and Technology, Vol. 100, 1994, pp. 123-139.

[6] Chen, Y.-C, Chang, C.-C., Pan, K.-L., and Yang, J.-T., "Flame lift-off and stabilization mechanisms of nonpremixed jet flames in a bluff-body burner", Combustion and Flame, Vol. 115, 1998, pp. 51-65.

[7] Chin, L.P. and Tankin, R.S., "Vortical structures in a 2-d vertical bluff-body burner", Combustion Science and Technology, Vol. 80, 1991, pp. 207-229.

[8] Masri, A. R., Kelman, J. B., and Dally, B. B., "The instantaneous spatial structure of the recirculation zone in bluff-body stabilized flames", Symposium (International) on Combustion, Vol. 27, Issue 1, 1998, pp. 1031-1038.

[9] Yang, J.-T., Chang, C.-C., Pan, K.-L, and Kang, Y.-P., "Thermal analysis and PLIF imaging of reaction flow behind a disc stabilizer with a central fuel jet", Combustion Science and Technology, Vol. 174, 2002, pp. 71-92.

[10] Yang, J.-T., Chang, C.-C., and Pan, K.-L, "Flow Structures and Mixing Mechanisms Behind a Disc Stabilizer With a Central Fuel Jet", Combustion Science and Technology, Vol. 174, 2002, pp. 93-124.

[11] C. K. Law, "Mechanisms of flame stabilization in subsonic and supersonic flows", Major Research Topics in Combustion, edited by M. Y. Hussaini, A. Kumar and R. G. Voigt, SpringerVerlag, New York, 1992, pp. 201-236.

[12] Cheng, T. S., Wehrmeyer, J. A., Pitz, R. W., Jarrett, O. Jr., and Northam, G. B, "Raman measurement of mixing and finite-rate chemistry in a supersonic hydrogen-air diffusion flame", Combustion and Flame, Vol. 99, 1994, pp. 157-173.

[13] Driscoll, J. F., Huh, H., Yoon, Y., and Donbar, J., "Measured Lengths of Supersonic Hydrogen-Air Jet FlamesCompared to Subsonic Flame Lengths-and Analysis", Combustion and Flame, Vol. 107, 1996, pp. 176-186.

[14] Bryant, R. A., Ratner, A., and Driscoll, J. F., "Using PLIF determined flame structure to analyze supersonic combustion efficiencies", AIAA-1999-445, 37th Aerospace Sciences Meeting and Exhibit, Reno, NV, 1999. 
[15] Yoon, Y., Donbar, J. M., and Driscoll, J. F., "Blowout Stability Limits of a Hydrogen Jet Flame within a Supersonic Heated, Coflowing Air Stream", Combustion Science and Technology, Vol. 97, 1994, pp. 137-156.

[16] Masri. A.R., Dibble, R.W., and Barlow, R.S., "Raman-Rayleigh Measurements in Bluff-Body Stabilized Flames of Hydrocarbon Fuels", Symposium (International) on Combustion, Vol. 24, Issue 1, 1992, pp. 317-324.

[17] Takahashi, F. and Schmoll, W.J., "Lifting criteria of jet diffusion flames", Symposium (International) on Combustion, Vol. 23, Issue 1, 1991, pp. 677-683.

[18] Choi, J. Y., Jeung, I. S. and Yoon, Y., "Numerical Study of SCRam-Accelerator Starting Characteristics", AIAA Journal, Vol. 36, No. 6, 1998, pp. 1029-1038.

[19] Menter, F.R., "Two-equation eddy-viscosity turbulence models for engineering applications", AIAA Journal, Vol. 32, 1994, pp. 1598-1605.

[20] Choi, J. Y., Jeung, I. S., and Yoon, Y., "Scaling effect of the combustion induced by shock-wave boundary-layer interaction in premixed gas", Symposium (International) on Combustion, Vol. 27, Issue 2, 1998, pp. 2181-2188.

[21] Seitzman, J. M., Ungut, A., Paul, P. H., and Hanson, R. K., "Imaging and characterization of $\mathrm{OH}$ structures in a turbulent nonpremixed flame", Symposium (International) on Combustion, Vol. 23, Issue 1, 1991, pp. 637-644.

[22] Turns, S. R., An Introduction to Combustion, MacGraw-Hill, New York, 1996.

[23] Vranos, A., Taback, E.D., and Shipman, C.W., "An experimental study of the stability of hydrogen-air diffusion flames", Combustion and Flame, Vol. 12, 1968, pp. 253-260.

[24] Huh, H. and Driscoll, J.F, "Shock-waveenhancement of the mixing and the stability limits of supersonic hydrogen-air jet flames", Symposium (International) on Combustion, Vol. 26, Issue 2, 1996, pp. 2933-2939.

[25] Badrinarayana, M. A., "An experimental investigation of base flows at supersonic speeds", Journal of the Royal Aeronautical Society, Vol. 65, 1961, pp. 475-481.

[26] Wagner, B. and White, R. A,, "Supersonic Base Flow Problem in Presence of an Exhaust Jet", AIAA Journal, Vol. 18, 1980, pp. 876-882.

[27] Donbar, J. M., Driscoll, J. F. and Carter, C. D., "Reaction zone structure in turbulent nonpremixed jet flames-from CH-OH PLIF images", Combustion and Flame, Vol. 122, 2000, pp. 1-19. 